\title{
Mapping Engineering Development Processes for Process Improvement
}

\author{
Aileen J Lim, W. Patrick Neumann, Filippo A. Salustri \\ Department of Mechanical and Industrial Engineering \\ Ryerson University \\ alim@ryerson.ca \\ pneumann@ryerson.ca \\ salustri@ryerson.ca
}

\begin{abstract}
Integrating human factors considerations into the design of production systems can improve productivity and quality results while reducing injury risks to system operators. The researchers are currently conducting an action research study with a Canadian electronics manufacturer to improve their production system design process (PSDP), and thereby their production systems, by integrating human factors (HF). One of the first requirements is a clear understanding of the PSDP as a means of identifying and coordinating process improvements. Since there is no accepted approach to PSDP 'mapping', methodological development is needed. A proposed methodology for assessment of PSDPs is described.

Data collection includes a combination of interview, observational, and document sources. Analysis uses a general inductive approach to develop a process 'map'. Mapping options to be assessed for utility include decision trees, cross-functional diagrams, actor-network analyses and concept maps. The developed map will then be verified by company personnel and subsequently used in developmental workshops to help the design team identify possible process improvements. As part of the 'action research' methodology, researchers will make observations and field notes to better understand how such process maps can best be created and communicated to company personnel. Challenges include gaining access to confidential company data, and experience shows that the active participation of company personnel in data collection speeds and enhances this process. The utility of the PSDP maps to support process improvement efforts remains to be studied.
\end{abstract}

\section{Introduction}

Work system design practices tend to be performancefocused and don't always include attention to human factors (HF). Considering humans in work system design has the potential to help companies improve their performance in ways that are humanly sustainable, that is, HF can help to prevent quality and productivity problems while eliminating health hazards for employees.

\subsection{Problem}

Industry Canada statistics state that $75 \%$ of Manufacturing employees, or greater than 1.3 million individuals in Canada, work in Production [1], and are at risk within an industry which has the highest number of work-related injuries per year [2]. It has been estimated that the direct and indirect costs of work-related ill health are about the same as those for all cancers combined [3]. These high total costs and injury costs alone do not even account for performance declines of injured workers. There exists a growing body of research studies demonstrating how attention to human factors can serve a wide range of organisational objectives providing strategic advantage to the firm including improved productivity, improved quality, contribution to "Corporate Social Responsibility' agendas, and improved flexibility of the organisation [4].

At the $3^{\text {rd }}$ CDEN/RCCI Conference in 2006, Neumann and Winkel presented a relevant case study examining the distribution of responsibility for human factors at Volvo Power Train in Sweden based on a previous action research case study [5]. In this paper, 'design' was emphasized at three levels: 1) Product Design, 2) Process (Production System) Design, and 3) Organizational Design. It was found that decisions made at each of these levels have the potential to influence human factors in the resulting work system and thus contribute to the elimination, or creation, of work-related ill health. Furthermore, choices made at each stage by employees in engineering design had an effect on HF conditions for system operators, indicating a need to improve coordination between the different design stakeholders throughout the process for more sustainable solutions. Sustainability of work 
systems that use employee's physical and mental resources no faster than the employee can regenerate them [6] is an important design criterion in a modern working world marked by two decades of intensification of work [7]. There is little guidance in the literature as to how companies can adapt their production system design processes (PSDP) in order to accommodate the criteria of human sustainability.

Many researchers have noted a need for early inclusion of $\mathrm{HF}$ in production system design, as decisions in production system design lead to risk factors. The Ministry of Labour's 'Ontario Subcommittee on Ergonomics' (OSE) has stated that "A proactive approach and early intervention strategies are integral to the reduction and elimination of the incidence of work-related MSD (musculoskeletal disorder)" [8]. In practise, the design activity is inextricably woven into the product development process, and any changes to design activities usually have far-reaching implications for the organization. Early inclusion in design would eliminate injuries and high retrofitting expenses at later stages in design, and would allow for more options for better solutions. Organisations should aim for systems where quality and performance are not compromised by poor HF.

\subsection{Scope of Study}

In collaboration with a major Canadian electronics manufacturer, the researchers are investigating how to assess work system design processes with respect to both traditional technical as well as crucial HF concerns that determine both performance and operator sustainability. The overarching aim of this project is to study the uptake and application of ergonomics science into the organizational production system development process. This study will contribute to an understanding of how human factors can be effectively integrated into real-world product development processes, an area lacking research. Such an integrated application approach is a prerequisite to documenting the full performance benefits available from the design of sustainable production systems. Drawing upon insight gained from the Neumann and Winkle paper [5], the project will address the organizational design aspect, and as a result product and process design will be indirectly studied. The objective of the larger study, which operates in a collaborative 'action research' mode [9], is to contribute to and study the factors influencing the success of an organisational change effort to integrate
HF into the participating company's production system development process, and support organizational learning [10]. The ongoing collaboration (with research and company personnel as co-investigators) allows the study of the change process from a close 'embedded' position. This provides researchers with good insight into what works (and doesn't work) in the effort to help the company learn to develop their production system design process. This approach serves both the immediate needs of the company for an improved PSDP as well as the longer-term needs of research to develop better ways to help companies improve their PSDPs.

As the first stage to the larger case study, this methodological paper describes an approach to the creation of a 'map' of the PSDP currently in use at a major Canadian electronics manufacturer. This 'mapping' approach is intended to help the company and research team identify opportunities for improvement to the PSDP. This assessment of the current PSDP provides a start-point for organisational development. By generating and sharing such a PSDP analysis with company stakeholders we are able to create a common understanding of the PSDP and use this understanding as a basis for decisions on how best to develop the PSDP based on the analysis. This initial step in the larger project was chosen collaboratively with company personnel who note that a documented, comprehensive description of the current process does not exist in the company. This paper is an early stage report on methodology aiming to gain feedback and input from the Engineering Design community at CDEN.

\section{Methodology}

The main objective of this first stage in the larger longitudinal case study is to gain an understanding of the company's current PSDP in terms of gaps, barriers, facilitators and opportunities for HF considerations, through internal analysis. As there are no generally accepted approaches to the studying, assessing and mapping of PSDPs, this project entails methodological development. An explorative, primarily qualitative mixed-methods approach is being developed with a basis in program evaluation science, namely utilization-focused evaluation [11]. The analysis described here will be updated at the end of the larger project to provide insight into the extent to which the PSDP has changed over the course of the period of study. 


\subsection{Data Collection and Analysis}

Data will be collected to gain an understanding of the PSDP for mapping purposes, and will be done jointly with company personnel including the project coordinators (one Ergonomist and one Engineer) who are assigned to this project. Qualitative data will be collected from three sources: interviews, observation, and review of company documents as outlined by Patton [12].

1. Interviews: Key informants will be identified for interview by company personnel recommendation and/or researcher discretion based on a cumulative understanding of the organization, and meetings will be scheduled by the project coordinators. Hour-long open-ended and semi-structured interviews with the key individuals will be conducted to understand stakeholders' perspectives on key issues such as employee and departmental roles and critical decision responsibility, collaboration between departments, information flow, tools used and challenges faced. The interviews focus on the current PSDP as practiced including a focus on both HF and other performancerelated topics, and are the primary source of information for the mapping activity. Follow-up questions and issues will be conducted by telephone for clarity as needed. The interviews will be taped using digital audio recorder, and transcribed for analysis. Transcribed data will be coded thematically using NVIVO qualitative analysis software. Company employees will be approached with follow-up questions as the project and new understandings develop, providing an iterative element to the investigation of current practices in the company. This data provides insight into progressive chains-of-events within the organization from design to production, and also increases awareness of the project and participation by stakeholders.

2. Observation: Observations of each site visit will be made using detailed field notes occasionally backed up by tape recordings of meetings and discussions with key stakeholders throughout the study period. Observations may take the form of perception of attitudes or reactions to discussions, mention of relevant past or present events or changes, or simply physical changes within the facility offices or production floor. Complementary observation of the current production systems will support the interview process by allowing knowledgeable discussion about the design of different aspects of the physical system.

3. Company Documents: Researchers will attempt to acquire company documents of relevance, and will study them when made available by the company. This process also requires navigating the company's confidentiality and secrecy policies surrounding the protection of company intellectual property and advantageous company routines.

This study applies the general inductive approach for analyzing qualitative evaluation data outlined by Thomas [13]. As data is collected, emergent themes will be coded manually and using qualitative data analysis software. Analyzed data will be verified with company personnel in order to ensure validity, through review of notes, process maps, and workshops further described below. Coded data will be complemented by verified field notes created throughout the project which will incorporate data analysis from all three sources of information.

\subsection{Process Mapping}

Design is a complex, multifaceted process with many issues and stakeholders, and is not easy to describe or 'capture' as a linear process. The creation of a PSDP 'map' is required in order to communicate the actual PSDP to the stakeholders involved. It is intended to provide a basis for discussion of how the PSDP might be improved, as well as a potential source of ideas around what opportunities for improvement currently exist - in this case with special reference to HF. We will be attempting to identify optimal approaches to visualizing and communicating critical aspects of the PSDP to the company personnel. The identification of these useful approaches for communicating and improving PDSPs is one of the research objectives for this sub-project.

As themes emerge during data collection and analysis, the process stages and stakeholders involved will be studied to determine information inputs and outputs at each stage of development with special attention to HF, design constraints and known opportunities for improvement. Researchers will attempt to develop a map to illustrate this information visually. Mapping of the work systems design process is a work in progress that will support integration of HF (including mental and physical aspects of work) in engineering design. In order to understand how best to communicate the current design process state to company stakeholders, a number of analysis approaches will be explored and discussed. The team will attempt to illustrate valuable information such as decision sequences (from decision trees), departmental collaborations (from cross-functional diagrams), role contributions (from actor-network analysis), and inputs/outputs of information flow (from concept 
maps). Furthermore, the researchers will use the map to illustrate where performance and process indicators exist, and where they are needed. Each of these forms of representation of the PSDP will be shared subsequently with the company for both verification of the map and for identification of future improvement actions.

\subsection{PSDP 'Map' verification}

Verification meetings will be held with key personnel prior to the workshops (described in Section 2.4), in order to gain a better understanding of the processes involved and ensure the data is valid. Initial data collection has already identified some aspects of the PSDP that are perceived differently by different stakeholders. This apparent conflict requires resolution to determine how the process actually runs, and to identify possible variances within the process itself. To this end, meetings with key stakeholders are planned to review the analysis and examine specific areas of conflict. This round of interaction will also ensure both that the analysis is fair and valid as well as help identify how best to present and communicate the result to the company. In order to achieve this, these events will also be subject to continuous note-taking supported by audio recordings which can then also be analyzed in order to inform the change effort in the larger action research project.

\subsection{Workshop Studies}

Building on the experience of the Volvo Powertrain Sweden study [14], the researchers designed this project with workshops to engage actors from different organisational groups in reviewing current practice and jointly identifying new opportunities for improvement. Such events are seen as a useful means to engage stakeholders and coordinate activities on issues, such as ergonomics for example, that span different organisational boundaries [15]. Workshops are a tool for organisational change and create a forum for cross-functional dialogue that does not normally exist. This participatory forum fosters group decision making, or at least group improvement identification depending on the decision maker power structure. Any eventual solution must serve the needs of multiple groups and stakeholders so it is best they are part of generating plans for action so they can better understand the need for the change and also identify change approaches that mesh well with their existing routines [16].
Workshops held with key cross-functional personnel will be recorded and subsequently analyzed. Participating personnel will be responsible to follow up on any action items agreed upon in the meeting. The map will then be updated using the data and documentation, and used as a tool for communication and analysis at the next major workshop. The process mapping activities and workshops will be held in parallel in order to iteratively incorporate and improve the company feedback within the map and project. Periodic discussion with researchers and company partners will take place throughout the project in order to facilitate ongoing learning.

The observation of these workshops is also an opportunity for data collection. In this phase we will continue to make field notes of our observations, as well as recordings of the discussions and decisions for action. This data will be subjected to further analysis in a similar manner to the PSDP data. The aim here is to understand what elements of the PSDP map presentations were favoured by the participants, what issues were identified for action, and what factor influenced the steps to integrate $\mathrm{HF}$ aspects into the PSDP.

\section{Discussion}

With no generally accepted approaches to the studying, assessing and mapping of PSDPs, the researchers drew on general program evaluation theory [11] as earlier described. The action research (AR) approach taken is generally uncommon in engineering design research, but has shown to be useful in studying organisational change. $A R$ is sometimes not well recognised or appreciated by researchers steeped in more traditional positivistic research paradigms. However, AR was employed as it is solution-focused without abandoning the need for transferrable knowledge gains that can be used in other companies. We are currently testing this novel approach to PSDP evaluation.

\subsection{Methodology}

Though this study is currently in progress and it may be too early to provide prescriptive advice, some insight can be drawn based on the work to date in terms of setting project scope, data collection, scheduling, use of metrics, and our experience with the action research approach. 
Scope - The PSDP is driven by product development, meaning that it is not a discrete event that takes place independent from other business processes. The company also launches multiple new products per year with several cross-functional teams resulting in some variances in the PSDP. Given this, there may be a need to focus evaluation on a single product launch in order to get a clear initial image of the PSDP.

Data Collection - The methodology applied yielded great insight into PSDP, however gaining acceptance and trust within the organization took time. At first, employees were hesitant to openly communicate opinions and provide supporting documents, which slowed down researcher learning of how things worked. In the interviews, employees seemed open to being recorded, which made it easier to more effectively participate in the interviews within the allocated time slot. One limitation of the sampling approach is the narrow view of the PSDP as researchers only get the perspectives of the employees selected for interviews and discussion. The researchers aim to "fill the gaps" in the process with the workshop studies. Overall, the presence of the company coordinators during data collection allowed for smoother discussions and great insight.

Scheduling - Some difficulties were encountered in regards to scheduling. Employees were open to allocating time towards the project, but periods of large gaps between site visits resulted in a significant amount of information lost on organizational changes due to the fast-paced environment. We soon learned that the 'target' was dynamic, and the PSDP was continuously evolving at this site. This complication requires ongoing discussions with the coordinators to update the research team on recent events and formal changes in the PSDP.

Metrics - We found that metrics were an area in need of development at the company. Determining metrics became a major aspect to data collection, and will be a source for comparing the earlier PSDP map to the updated version. As a result, a new sub-project has been initiated to help the company develop their metrics, particularly around human factors in the production system of which there were almost no leading indicators available - a situation typical in many companies.

Action Research - Within the action research agenda, we have strong support from the company including a Senior Director of Engineering and a Manager of Environmental Health and Safety as co- investigators, and company coordinators representing both engineering and ergonomics. The Company's employees have a very open and enthusiastic attitude towards the project. They are positive towards the 'mapping' activity and have given great feedback and insight during the project especially as time progressed. As a benefit of the AR approach, the researchers and company experience ongoing learning together with unlikely dependence upon completion of the project.

\subsection{Future Applications}

Information regarding the production system development process is being extracted using action research coupled with the general inductive approach for qualitative analysis. Analyzed data will then be translated to a multi-disciplinary process map as a communication tool for workshop discussions. With this, companies can improve their PSDPs - facilitated by discussions of how the system currently works. Though this particular study was focused on a manufacturing case, the methodology described may be applied to other applications. The researchers aim to take the lessons learned within this case study and establish a replicable generaliseable approach to map PSDPs, thereby helping companies develop their processes and work systems to be efficient and of high quality, as well as sustainable for operators.

It should be noted that there may be context sensitivity in future studies. A large contributor to the success to date of using this method may have been the particular company-researcher dynamics. In this case, the study was rather successful due to the strong company backing and willingness to support the project with their resources. Despite this limitation, this study has demonstrated and described the potential for such an application of process mapping or design process audit with reference to HF.

\section{Conclusion}

There is need and opportunity to integrate human factors considerations into the production system development process, in order to proactively prevent risks to performance, quality, and operator health. However, this human factors integration requires an understanding of the development process under study before improvements could be chosen. This paper outlines an approach being developed to 'mapping' PSDPs using attributes of various existing tools such as decision trees, cross-functional diagrams, actornetwork analyses and concept maps. The map will be 
created based on qualitative data collected through interviews, observation and document analysis, and will be verified through meetings and workshops. The aim is to learn how to help companies identify opportunities to improve their PDSP and thereby develop superior production systems.

Future researchers may encounter difficulties with accessing documents. This is mitigated by active participation of company personnel in data collection. Further development is needed to determine optimal approaches to visualising and communicating PSDP maps, which we are currently testing in a longitudinal case study. This approach to PSDP 'mapping' will subsequently be evaluated for its ability to serve as a tool for organizational learning in PSDP development.

\section{References}

[1] Industry Canada (2008), Canadian Industry Statistics. Retrieved June 12, 2009 from http://www.ic.gc.ca/cissic/cis-sic.nsf/IDE/cis31-33empe.html.

[2] Human Resources and Skills Development Canada (2009), Work-Related Injuries. Retrieved June 12, 2009 from http://www4.hrsdc.gc.ca/.3ndic.1t.4r@-eng.jsp?iid=20.

[3] Leigh, J. P., Markowitz, S. B., Fahs, M., Shin, C. and Landrigan, P. J. (1997) Occupational injury and illness in the United States - Estimates of costs, morbidity, and mortality. Archives of Internal Medicine, v157(14): 1557-68.

[4] Dul, J. and Neumann, W. P. (2009) Ergonomics Contributions to Company Strategies. Applied Ergonomics, v40(4): 745-752.

[5] Neumann, W.P., and Winkel, J. (2006, July). Who is responsible for Human Factors in Engineering Design? The Case of Volvo Powertrain. Paper presented at the Third CDEN/RCCI International Design Conference on Education, Innovation, and practice in Engineering Design, Toronto, ON.

[6] Docherty, P., Forslin, J. and Shani, A. B. (2002) Creating sustainable work systems : emerging perspectives and practice, Routledge, London. 0-415-28576-3
[7] Parent-Thirion, A., Macias, E. F., Hurley, J. and Vermeylen, G. (2007) "Fourth European Working Conditions Survey" European Foundation for the Improvement of Living and Working Conditions. Retrieved from http://www.eurofound.europa.eu

[8] Ontario Ministry of Labour (2005) "Report to the Minister of Labour: Recommendations on strategies to reduce work-related musculoskeletal disorders in Ontario" Ergonomics Sub-Committee of the Manufacturing Panel, Health and Safety Action Group. The Government of Ontario, Ministry of Labour. Retrieved from http://www.labour.gov.on.ca/english/hs/ergonomics.

[9] Reason, P. and Bradbury, H. (2001) Handbook of Action Research, Sage, London. 0-7619-6645.

[10] Morgan, G. (2006). Images of Organization. (Updated ed.), Learning and Self-Organization-Organizations as Brains (pp. 71-114). Thousand Oaks (CA): Sage Publications, Inc.

[11] Patton, M.Q. (1997). Utilization-Focused Evaluation. ( $3^{\text {rd }}$ Edition). Thousand Oaks (CA): Sage Publications, Inc.

[12] Patton, M.Q. (2002). Qualitative Research \& Evaluation Methods. ( $3^{\text {rd }}$ Edition). Thousand Oaks (CA): Sage Publications, Inc.

[13] Thomas, D. R. (2006). A General Inductive Approach for Analyzing Qualitative Evaluation Data. American Journal of Evaluation, v27(2): 237-246.

[14] Neumann, W. P., Ekman, M. and Winkel, J. (2009) Integrating ergonomics into system development - The Volvo Powertrain Case. Applied Ergonomics, v40(3): 527537

[15] Ekman Philips, M. (2002) Dialog över etablerade gränser: om organisationsutveckling $i$ sjukvården, Arbetslivsinstitutet, Stockholm. ISSN 91-7045-647-X

[16] Ekman Philips, M. and Huzzard, T. (2007) Developmental magic? Two takes on a dialogue conference. Journal of Organizational Change management, v20(1): 825. 